\title{
Frequency of Anomalies and Hospital Outcomes in Infants with Gastroschisis and Omphalocele
}

\author{
Kristin M. Corey ${ }^{\mathrm{a}}$, Christoph P. Hornik, MD, MPH ${ }^{\mathrm{a}, \mathrm{b}}$, Matthew M. Laughon, MD, $\mathrm{MPH}^{\mathrm{c}}$, \\ Kerstin McHutchison, RN ${ }^{\mathrm{a}}$, Reese H. Clark, MD ${ }^{\mathrm{d}}$, and P. Brian Smith, MD, MPH, MHS ${ }^{a, b},{ }^{*}$ \\ aDuke Clinical Research Institute, Durham, NC, USA \\ bDepartment of Pediatrics, Duke University, Durham, NC, USA \\ 'Department of Pediatrics, University of North Carolina, Chapel Hill, NC, USA \\ dPediatrix Medical Group, The Center for Research, Education, and Quality, Sunrise, FL, USA
}

\section{Abstract}

Background-Gastroschisis and omphalocele are the most common anterior abdominal wall defects affecting infants. There are few large cohort studies describing the frequency of associated anomalies in infants with these 2 conditions. We describe associated anomalies and outcomes in infants with these defects using a large, multi-center clinical database.

Methods-We identified all infants with gastroschisis or omphalocele from a prospectively collected database of infants discharged from 348 neonatal intensive care units in North America from 1997-2012. Maternal and patient demographic data, associated anomalies, and outcome data were compared between infants with gastroschisis and omphalocele.

Results-A total of 4687 infants with gastroschisis and 1448 infants with omphalocele were identified. Infants with omphalocele were more likely to be diagnosed with at least 1 other anomaly compared with infants with gastroschisis ( $35 \%$ vs. $8 \%$, p <0.001). Infants with omphalocele were more likely to develop pulmonary hypertension compared with those with gastroschisis (odds ratio [OR] 7.78; 95\% confidence interval 5.81, 10.41) and had higher overall mortality (OR $6.81[5.33,8.71])$.

Conclusion-Infants with omphalocele were more likely to have other anomalies, be diagnosed with pulmonary hypertension, and have higher mortality than infants with gastroschisis.

\section{Keywords}

gastroschisis; omphalocele; anomalies; outcomes

() 2014 Elsevier Ireland Ltd. All rights reserved.

*Corresponding author at: Duke Clinical Research Institute, Box 17969, Durham, NC 27715; phone 919-668-8951; brian.smith@duke.edu.

Publisher's Disclaimer: This is a PDF file of an unedited manuscript that has been accepted for publication. As a service to our customers we are providing this early version of the manuscript. The manuscript will undergo copyediting, typesetting, and review of the resulting proof before it is published in its final citable form. Please note that during the production process errors may be discovered which could affect the content, and all legal disclaimers that apply to the journal pertain.

Conflict of interest statement

The remaining authors have no potential conflicts to report. 


\section{Introduction}

Gastroschisis and omphalocele are the most common anterior abdominal wall defects in infants, with estimated incidences of 1:4000 live-births for omphalocele and 1:12,000 livebirths for gastroschisis [1,2]. Gastroschisis is an abdominal wall defect in which the small intestine, and occasionally the stomach or colon, is outside of the body without a membranous protective sac [3]. Omphalocele is a midline abdominal wall defect in which a thin membrane surrounds the protruding organs that can include small intestine, liver, bladder, spleen, stomach, uterus, and ovaries [4].

Gastroschisis is associated with environmental factors such as teratogens, poor prenatal care, maternal infections, and younger maternal age [3]. Although intestinal atresias are found in as many as $28 \%$ of infants, non-intestinal anomalies are reported to be rare [4,5]. Infants with omphalocele have a $>50 \%$ risk of having a genetic anomaly, and this defect is described in association with a number of genetic syndromes including trisomy 13,18, and 21, and Beckwith-Wiedemann syndrome [4]. Non-intestinal anomalies, including cardiac defects and pulmonary hypoplasia, are reported in up to $24 \%$ of infants with omphalocele [6].

Associated anomalies and clinical outcomes in both conditions have been described in single-center studies [7-10]. These studies suggest that the overall survival of infants with gastroschisis is $92-96 \%$ and that their prognosis is determined by the degree of injury to the bowel, severity of illness in the first week of life, and the immediate post-operative recovery $[10,11]$. Mortality in infants with omphalocele is higher $(20 \%)$ and may be related to the presence or absence of other anomalies including intestinal atresia, cardiac defects, or pulmonary hypoplasia $[4,12]$.

We sought to describe anomalies and outcomes associated with gastroschisis and omphalocele and the early hospital outcomes of both conditions using data from a large, multi-center clinical database.

\section{Methods}

\subsection{Study cohort}

We evaluated data from all infants diagnosed with either gastroschisis or omphalocele discharged from 348 neonatal intensive care units (NICUs) in North America managed by the Pediatrix Medical Group from 1997-2012. Data are entered into the database using a computer-assisted tool that generates clinical notes. We collected both maternal and infant data including: gestational age (GA), birth weight, mode of delivery, concomitant diagnoses, Apgar score at 5 minutes, sex, race, age in days at first feeding, mechanical ventilation, medication use, total length of hospitalization, and mortality at discharge.

\subsection{Definitions}

Anomalies, including gastroschisis and omphalocele, were diagnosed by the treating neonatologists at each site during the normal clinical care of the infant. We defined major 
congenital anomaly as an anomaly presenting at birth that was any of the following: lethal, life-shortening, life-threatening, requiring major surgery, or affecting the infant's quality of life in a significant way $[13,14]$. We classified anomalies as cardiovascular, pulmonary, neurologic, gastrointestinal, renal, hematologic, genetic, or other. We defined first day of enteral feedings as the first day of life an infant received any type or amount of enteral nutrition. We defined duration of mechanical ventilation as the total duration of mechanical ventilation (conventional or high-frequency) during the hospitalization. We defined pulmonary hypertension as any reported diagnosis of pulmonary hypertension or exposure to inhaled nitric oxide (iNO) or sildenafil at any time during the infant's hospitalization.

\subsection{Statistical analysis}

The unit of observation for this analysis was the infant. We used standard summary statistics to describe infant characteristics and associated anomalies. We used chi square, Fisher's exact, and Wilcoxon rank sum tests where appropriate to compare demographic characteristics or outcomes and the presence of associated anomalies between infants with gastroschisis and those with omphalocele. We used multivariable linear and logistic regression controlling for GA to evaluate the association between gastroschisis or omphalocele and the outcomes of mortality, length of mechanical ventilation, length of hospitalization, days to first enteral feeding, and diagnosis of pulmonary hypertension. We plotted survival probabilities using the Kaplan-Meier method.

We conducted all analyses using Stata 12.0 (College Station, TX) and considered a $\mathrm{p}<0.05$ to be statistically significant. Permission to conduct this analysis was provided by the Duke University Institutional Review Board.

\section{Results}

We identified 1448 infants with omphalocele and 4687 infants with gastroschisis (Table 1). Infants with omphalocele had a higher median birth weight (2824 $\mathrm{g}$ [interquartile range: $2205,3340]$ vs. $2370 \mathrm{~g}$ [2041, 2734], p<0.001) and GA (37 weeks [35, 39] vs. 36 weeks [35, 37], $\mathrm{p}<0.001)$ compared with infants with gastroschisis. Infants with omphalocele were less likely to be premature ( $<37$ weeks GA) compared to those with gastroschisis $(582 / 1448$ [40\%] vs. $3049 / 4687$ [65\%], p<0.001).

The majority of infants did not have additional anomalies (5257/6135 [86\%]). We identified 1282 anomalies in 878 infants. Of the 6135 infants, 257 (4\%) had >1 anomaly. Infants with omphalocele were more likely to be diagnosed with at least 1 other anomaly than those with gastroschisis (513/1448 [35\%] vs. 365/4687 [8\%], $\mathrm{p}<0.001)$. This was true for all anomaly categories (Table 2).

In infants with known status at hospital discharge, mortality was higher in those with omphalocele vs. those with gastroschisis (191/1049 [18\%] vs. 143/3287 [4\%], p<0.001) (Table 3 and Fig. 1). The median length of hospitalization for the entire cohort of survivors was 31 days (interquartile range: 22, 50 days). Among survivors, median length of hospitalization was shorter for infants with omphalocele than for those with gastroschisis (17 days [9, 36] vs. 33 days $[24,52], \mathrm{p}<0.001)$. Infants with omphalocele who survived to 
hospital discharge were started on their first feeds at an earlier postnatal age (median 6 days $[3,10]$ vs. 15 days $[11,21], \mathrm{p}<0.001)$ and had a shorter duration of mechanical ventilation (median 2 days $[0,5]$ vs. 4 days $[2,8], \mathrm{p}<0.001)$ compared with infants with gastroschisis.

A total of 195 infants were diagnosed with pulmonary hypertension (Table 3). Infants with omphalocele were more frequently diagnosed with pulmonary hypertension (134/1448 [9\%] vs. 61/4687 [1\%], p <0.001) and more frequently received pulmonary vasodilating agents such as iNO (57/1448 [4\%] vs. 33/4687 [1\%], p<0.001) or sildenafil (10/1448 [1\%] vs. $0 / 4687[<0 \%], p<0.001$ ) than infants with gastroschisis (Table 3). For infants with known status at hospital discharge, mortality was higher in those with evidence of pulmonary hypertension (diagnosis of pulmonary hypertension or treatment with sildenafil or iNO) compared to those without (68/173 [20\%] vs. 266/4703 [6\%], p<0.001). Infants with omphalocele and evidence of pulmonary hypertension had higher mortality compared with those with gastroschisis and evidence of pulmonary hypertension (51/113 [45\%] vs. 17/60 [28\%], $\mathrm{p}=0.03)$.

\section{Discussion}

We described associated anomalies and short-term clinical outcomes of a large cohort of infants with omphalocele or gastroschisis. Similar to prior reports, we observed that infants with omphalocele were more frequently diagnosed with associated anomalies and that mortality was higher in infants with omphalocele compared with those with gastroschisis. In addition, we found that, among survivors, length of hospitalization was significantly longer for infants with gastroschisis compared with those with omphalocele. Lastly, infants with omphalocele were more likely to be diagnosed with pulmonary hypertension.

There is a known association between genetic disease and omphalocele. Several case reports have described multiple members within a family being affected with omphalocele [15-17]. In a single-center study of abdominal wall defects diagnosed in utero, chromosomal abnormalities were found by karyotype in $8 / 29$ (28\%) fetuses with omphalocele [18]. We observed a somewhat lower proportion of genetic syndromes in our larger cohort of infants with omphalocele (15\%) but found that infants who were diagnosed with omphalocele were $>10$ times more likely to have genetic disease, including Beckwith-Wiedemann syndrome and trisomies 13 and 18, compared with infants diagnosed with gastroschisis. Infants with omphalocele also had a significantly higher likelihood of having non-intestinal manifestations of disease, with the cardiac, renal, pulmonary, and neurologic systems being affected. This observation is likely related to the higher rate of multi-organ systems involvement in those with genetic syndromes.

Despite the higher prevalence of anomalies in infants with omphalocele, the proportion of infants with gastroschisis diagnosed with at least 1 anomaly was significant at 365/4687 $(8 \%)$. This proportion is comparable to that reported from the National Inpatient Sample and Kids' Inpatient Database, where a total of 4344 infants with gastroschisis were identified using ICD-9 codes from 1988-2003, and complex gastroschisis cases, defined as the presence of associated gastrointestinal anomalies, represented $11 \%$ of the entire cohort [5]. 
In our cohort, infants with omphalocele were at significantly higher risk of having pulmonary hypertension compared with those with gastroschisis. Pulmonary hypertension and other chronic pulmonary complications have been previously described in several case reports or case series of infants with omphalocele $[7,19,20]$. The etiology of pulmonary hypertension in these infants is likely multifactorial. Pulmonary hypoplasia is the most commonly described etiology of pulmonary hypertension found on autopsy in 14/27 infants with giant omphalocele [19]. Alveolar capillary dysplasia has been suggested as the etiology of pulmonary hypertension in another case [19]. Due to the association with congenital heart disease, pulmonary hypertension may also be related to pulmonary over-circulation from left to right shunts or structural abnormalities of the pulmonary arteries, though this is likely to be a later finding [21].

We found that mortality in infants with omphalocele was considerably higher than in those with gastroschisis. This finding is consistent with surgical reports of mortality in gastroschisis being as low as $4 \%$, significantly lower than for infants with omphalocele (8$33 \%$ ) [22]. In our series, mortality was highest for infants with omphalocele diagnosed with pulmonary hypertension (45\%)—considerably higher than mortality in all infants with omphalocele (18\%) and in infants with gastroschisis diagnosed with pulmonary hypertension $(28 \%)$.

Survivors with gastroschisis had a longer length of hospitalization compared with survivors with omphalocele. While our study does not allow us to identify the exact reason for prolonged hospitalization, the earlier initiation of enteral feeds in infants with omphalocele may play a role. However, additional factors such as gastrointestinal dysmotility are known to significantly affect time to full enteral nutrition and likely play a significant role in timing of feeding initiation [4]. Trials of prokinetic agents have yielded mixed results, with duration to full enteral nutrition after gastroschisis repair reaching almost 1 month [23,24]. In a study of infants with gastroschisis or omphalocele identified in the same database from 19972007 , the relative proportion of total infant hospital days for patients with gastroschisis was found to be increasing over time, while that for patients with omphalocele remained constant [25]. The authors postulated that improved survival in infants with gastroschisis was associated with a higher rate of medical complexity of those survivors, which led to prolonged hospitalization.

Limitations of our study include those of any observational analysis, such as selection bias and potential confounders. We recognize that some malformations observed and corrected at the time of surgery may be underreported. For example, malrotation has been reported to occur in $8-9 \%$ of cases of gastroschisis and omphalocele and was reported in only $1 \%$ of our cohort [26]. We were not able to describe the size of the abdominal wall defects or the extent of involvement of intra-abdominal organs in the defects. Further, we did not have data available to assess the severity of cardiac, renal, pulmonary, neurologic, or genetic diagnoses nor did we have data regarding the degree of pulmonary hypertension as assessed by echo-Doppler or invasive measurements. We were therefore unable to adjust our analysis for the severity of an associated anomaly including pulmonary hypertension. Our analysis of pharmacologic therapy for pulmonary hypertension was further limited by the lack of 
information on medication dosing. Lastly, we did not have data on enteral feeding volume to describe differences in volume of enteral feeding and time to full enteral feeding.

In conclusion, this study, which used a large multi-center NICU database, demonstrated that infants with omphalocele had higher rates of genetic syndromes and extra-intestinal manifestations of disease, similar to previous smaller studies. In addition, we demonstrated that pulmonary hypertension was more frequently diagnosed in infants with omphalocele compared with those with gastroschisis. While the etiology of the pulmonary hypertension is likely multi-factorial, this is important information for those caring for these high-risk patients in terms of antenatal and preoperative counseling and perioperative management. In addition, these identified high-risk patients may be targeted for future clinical trials and interventions to reduce pulmonary hypertension.

\title{
Acknowledgments
}

\author{
Role of the funding source
}

Research reported in this publication was supported by the National Center for Advancing Translational Sciences of the National Institutes of Health under award number UL1TR001117. The content is solely the responsibility of the authors and does not necessarily represent the official views of the National Institutes of Health. The study sponsor played no role in the study design; in the collection, analysis, and interpretation of data; in the writing of the manuscript; or in the decision to submit the manuscript for publication.

M.M.L. receives support from the U.S. government for his work in pediatric and neonatal clinical pharmacology (Government Contract HHSN267200700051C, PI: Benjamin under the Best Pharmaceuticals for Children Act) and from NICHD (K23HD068497). P.B.S. receives salary support for research from the National Institutes of Health (NIH) and the National Center for Advancing Translational Sciences of the NIH (HHSN267200700051C, HHSN275201000003I, and UL1TR001117); he also receives research support from industry for neonatal and pediatric drug development (www.dcri.duke.edu/research/coi.jsp).

\section{References}

1. Laughon M, Meyer R, Bose C, Wall A, Otero E, Heerens A, et al. Rising birth prevalence of gastroschisis. J Perinatol. 2003; 23:291-293. [PubMed: 12774135]

2. Kilby MD. The incidence of gastroschisis. BMJ. 2006; 332:250-251. [PubMed: 16455699]

3. Baird PA, MacDonald EC. An epidemiologic study of congenital malformations of the anterior abdominal wall in more than half a million consecutive live births. Am J Hum Genet. 1981; 33:470478. [PubMed: 6454342]

4. Frolov P, Alali J, Klein MD. Clinical risk factors for gastroschisis and omphalocele in humans: a review of the literature. Pediatr Surg Int. 2010; 26:1135-1148. [PubMed: 20809116]

5. Christison-Lagay ER, Kelleher CM, Langer JC. Neonatal abdominal wall defects. Semin Fetal Neonatal Med. 2011; 16:164-172. [PubMed: 21474399]

6. Arnold MA, Chang DC, Nabaweesi R, Colombani PM, Bathurst MA, Mon KS, et al. Risk stratification of 4344 patients with gastroschisis into simple and complex categories. J Pediatr Surg. 2007; 42:1520-1525. [PubMed: 17848242]

7. Edwards EA, Broome S, Green S, Douglas C, McCall E, Nuthall G, et al. Long-term respiratory support in children with giant omphalocele. Anaesth Intensive Care. 2007; 35:94-98. [PubMed: 17323674]

8. Gerrits LC, De Mol AC, Bulten J, Van der Staak FH, Van Heijst AF. Omphalocele and alveolar capillary dysplasia: a new association. Pediatr Crit Care Med. 2010; 11:e36-e37. [PubMed: 20453609]

9. Gorra AS, Needelman H, Azarow KS, Roberts HJ, Jackson BJ, Cusick RA. Long-term neurodevelopmental outcomes in children born with gastroschisis: the tiebreaker. J Pediatr Surg. 2012; 47:125-129. [PubMed: 22244404] 
10. Kassa AM, Lilja HE. Predictors of postnatal outcome in neonates with gastroschisis. J Pediatr Surg. 2011; 46:2108-2114. [PubMed: 22075340]

11. Clark RH, Walker MW, Gauderer MW. Factors associated with mortality in neonates with gastroschisis. Eur J Pediatr Surg. 2011; 21:21-24. [PubMed: 21328190]

12. van Eijck FC, Hoogeveen YL, van Weel C, Rieu PN, Wijnen RM. Minor and giant omphalocele: long-term outcomes and quality of life. J Pediatr Surg. 2009; 44:1355-1359. [PubMed: 19573661]

13. Yang J, Cummings EA, O'Connell C, Jangaard K. Fetal and neonatal outcomes of diabetic pregnancies. Obstet Gynecol. 2006; 108(3 Pt 1):644-650. [PubMed: 16946226]

14. Idris N, Wong SF, Thomae M, Gardener G, McIntyre DH. Influence of polyhydramnios on perinatal outcome in pregestational diabetic pregnancies. Ultrasound Obstet Gynecol. 2010; 36:338-343. [PubMed: 20503236]

15. Islam S. Advances in surgery for abdominal wall defects: gastroschisis and omphalocele. Clin Perinatol. 2012; 39:375-386. [PubMed: 22682386]

16. Kanagawa SL, Begleiter ML, Ostlie DJ, Holcomb G, Drake W, Butler MG. Omphalocele in three generations with autosomal dominant transmission. J Med Genet. 2002; 39:184-185. [PubMed: 11897819]

17. Pryde PG, Greb A, Isada NB, Johnson MB, Klein M, Evans MI. Familial omphalocele: considerations in genetic counseling. Am J Med Genet. 1992; 44:624-627. [PubMed: 1481822]

18. Hidaka N, Murata M, Yumoto Y, Hojo S, Fujita Y, Masumoto K, et al. Characteristics and perinatal course of prenatally diagnosed fetal abdominal wall defects managed in a tertiary center in Japan. J Obstet Gynaecol Res. 2009; 35:40-47. [PubMed: 19215546]

19. Argyle JC. Pulmonary hypoplasia in infants with giant abdominal wall defects. Pediatr Pathol. 1989; 9:43-55. [PubMed: 2717498]

20. Miller OI, Gaynor JW, Macrae DJ, Tasker RC. Inhaled nitric oxide for pulmonary hypertension after repair of exomphalos. Arch Dis Child. 1993; 69(5 Spec No):518-520. [PubMed: 8285756]

21. Gibbin C, Touch S, Broth RE, Berghella V. Abdominal wall defects and congenital heart disease. Ultrasound Obstet Gynecol. 2003; 21:334-337. [PubMed: 12704739]

22. Vachharajani AJ, Rao R, Keswani S, Mathur AM. Outcomes of exomphalos: an institutional experience. Pediatr Surg Int. 2009; 25:139-144. [PubMed: 19066916]

23. Curry JI, Lander AD, Stringer MD. A multicenter, randomized, double-blind, placebo-controlled trial of the prokinetic agent erythromycin in the postoperative recovery of infants with gastroschisis. J Pediatr Surg. 2004; 39:565-569. [PubMed: 15065029]

24. Lander A, Redkar R, Nicholls G, Lawson A, Choudhury SR, Corkery JJ, et al. Cisapride reduces neonatal postoperative ileus: randomised placebo controlled trial. Arch Dis Child Fetal Neonatal Ed. 1997; 77:F119-F122. [PubMed: 9377133]

25. Clark RH, Walker MW, Gauderer MW. Prevalence of gastroschisis and associated hospital time continue to rise in neonates who are admitted for intensive care. J Pediatr Surg. 2009; 44:11081112. [PubMed: 19524725]

26. Forrester MB, Merz RD. Structural birth defects associated with omphalocele and gastroschisis, Hawaii, 1986-2001. Congenit Anom (Kyoto). 2008; 48:87-91. [PubMed: 18452490] 


\section{HIGHLIGHTS}

- Gastroschisis and omphalocele are the most common anterior abdominal wall defects affecting infants.

- In our study, infants with omphalocele were more likely to have other anomalies and have higher mortality than infants with gastroschisis.

- We also found that pulmonary hypertension was more frequently diagnosed in infants with omphalocele compared with those with gastroschisis. 


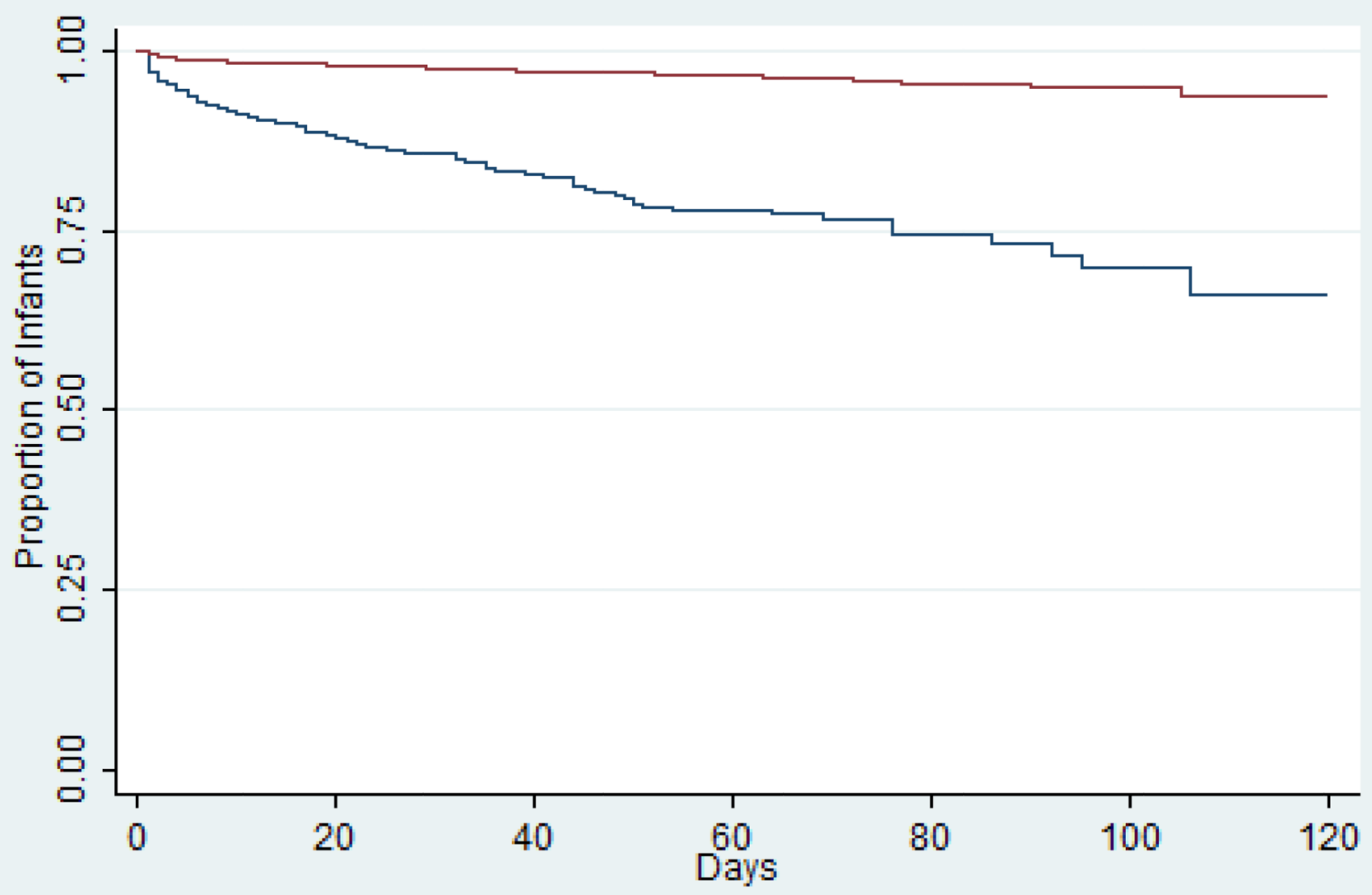

Fig. 1.

Kaplan-Meier curve demonstrating increased risk of mortality in infants with omphalocele compared with infants with gastroschisis. 


\section{Table 1}

Demographics

\begin{tabular}{|c|c|c|}
\hline & $\begin{array}{c}\text { Omphalocele } \\
(\mathrm{N}=1448)\end{array}$ & $\begin{array}{c}\text { Gastroschisis } \\
(\mathrm{N}=4687)\end{array}$ \\
\hline \multicolumn{3}{|l|}{ Birth weight (g) } \\
\hline$<1000$ & $34(2 \%)$ & $36(1 \%)$ \\
\hline $1000-1499$ & $80(6 \%)$ & $158(3 \%)$ \\
\hline $1500-2499$ & $381(26 \%)$ & $2574(55 \%)$ \\
\hline $2500-3499$ & $678(47 \%)$ & $1786(38 \%)$ \\
\hline$\geq 3500$ & $269(19 \%)$ & $126(3 \%)$ \\
\hline \multicolumn{3}{|l|}{ Gestational age (weeks) } \\
\hline$<25$ & $18(1 \%)$ & $10(<1 \%)$ \\
\hline $26-28$ & $31(2 \%)$ & $33(1 \%)$ \\
\hline $29-32$ & $129(9 \%)$ & $276(6 \%)$ \\
\hline $33-36$ & $404(28 \%)$ & $2730(58 \%)$ \\
\hline 237 & $866(60 \%)$ & $1637(35 \%)$ \\
\hline Male & $770(54 \%)$ & $2446(52 \%)$ \\
\hline \multicolumn{3}{|l|}{ Race/ethnicity } \\
\hline White & $789(57 \%)$ & $2497(56 \%)$ \\
\hline Black & $259(19 \%)$ & $392(9 \%)$ \\
\hline Hispanic & $261(19 \%)$ & $1334(30 \%)$ \\
\hline Other & $78(6 \%)$ & $253(6 \%)$ \\
\hline Inborn & $1201(84 \%)$ & $4188(89 \%)$ \\
\hline Cesarean section & $999(70 \%)$ & $3170(69 \%)$ \\
\hline \multicolumn{3}{|l|}{ 5-minute Apgar } \\
\hline $0-3$ & $42(3 \%)$ & $59(1 \%)$ \\
\hline $4-6$ & $126(9 \%)$ & $207(5 \%)$ \\
\hline $7-10$ & $1247(88 \%)$ & $4320(94 \%)$ \\
\hline
\end{tabular}

Early Hum Dev. Author manuscript; available in PMC 2015 August 01. 


\section{Table 2}

\section{Most common anomalies}

\begin{tabular}{|c|c|c|}
\hline & $\begin{array}{r}\text { Omphalocele } \\
(\mathbf{N}=1448)\end{array}$ & $\begin{array}{c}\text { Gastroschisis } \\
(\mathbf{N}=\mathbf{4 6 8 7})\end{array}$ \\
\hline Cardiac & $162(11 \%)$ & $35(1 \%)$ \\
\hline Pulmonary valve stenosis & $21(2 \%)$ & $9(<1 \%)$ \\
\hline Tetralogy of Fallot & $25(2 \%)$ & $0(0 \%)$ \\
\hline Coarctation of the aorta & $16(1 \%)$ & $6(<1 \%)$ \\
\hline Atrioventricular canal defect & $16(1 \%)$ & $1(<1 \%)$ \\
\hline Double-outlet right ventricle & $16(1 \%)$ & $0(0 \%)$ \\
\hline Gastrointestinal & $98(7 \%)$ & $216(5 \%)$ \\
\hline Malrotation & $20(1 \%)$ & $39(1 \%)$ \\
\hline Ileal atresia & $11(1 \%)$ & $50(1 \%)$ \\
\hline Imperforate anus & $49(3 \%)$ & $1(<1 \%)$ \\
\hline Bowel atresia & $2(<1 \%)$ & $38(1 \%)$ \\
\hline Jejunal atresia & $2(<1 \%)$ & $37(1 \%)$ \\
\hline Neurologic & $58(4 \%)$ & $35(1 \%)$ \\
\hline Meningomyelocele & $27(2 \%)$ & $5(<1 \%)$ \\
\hline Hydrocephalus & $15(1 \%)$ & $12(<1 \%)$ \\
\hline Dandy Walker malformation & $9(1 \%)$ & $2(<1 \%)$ \\
\hline Holoprosencephaly & $3(<1 \%)$ & $4(<1 \%)$ \\
\hline Septum pellucidum atresia & $0(0 \%)$ & $6(<1 \%)$ \\
\hline Pulmonary & $49(3 \%)$ & $14(<1 \%)$ \\
\hline Pulmonary hypoplasia & $50(3 \%)$ & $11(<1 \%)$ \\
\hline Pulmonary sequestration & $1(<1 \%)$ & $1(<1 \%)$ \\
\hline Robin sequence & $0(0 \%)$ & $1(<1 \%)$ \\
\hline Congenital lung cyst & $0(0 \%)$ & $1(<1 \%)$ \\
\hline Larynx anomaly & $1(0 \%)$ & $0(0 \%)$ \\
\hline Genetic & $220(15 \%)$ & $51(1 \%)$ \\
\hline Beckwith-Wiedemann syndrome & $84(6 \%)$ & $0(<1 \%)$ \\
\hline Chromosomal abnormality & $44(3 \%)$ & $16(<1 \%)$ \\
\hline Trisomy 13 & $37(3 \%)$ & $1(<1 \%)$ \\
\hline Trisomy 18 & $35(2 \%)$ & $1(<1 \%)$ \\
\hline Trisomy 21 & $15(1 \%)$ & $2(<1 \%)$ \\
\hline Renal & $80(6 \%)$ & $23(1 \%)$ \\
\hline Exstrophy of bladder & $48(3 \%)$ & $8(<1 \%)$ \\
\hline Ambiguous genitalia & $30(2 \%)$ & $3(<1 \%)$ \\
\hline Multicystic kidney & $6(<1 \%)$ & $5(<1 \%)$ \\
\hline Dysplastic kidney & $5(<1 \%)$ & $2(<1 \%)$ \\
\hline Obstructive uropathy & $4(<1 \%)$ & $3(<1 \%)$ \\
\hline
\end{tabular}

Early Hum Dev. Author manuscript; available in PMC 2015 August 01. 
Table 3

Clinical outcomes in infants with omphalocele vs. gastroschisis

\begin{tabular}{|c|c|c|c|}
\hline & $\begin{array}{c}\text { Omphalocele } \\
\mathbf{N}=1508\end{array}$ & $\begin{array}{c}\text { Gastroschisis } \\
\quad N=4773\end{array}$ & Adjusted odds ratio \\
\hline Death & $191(18 \%)$ & $143(4 \%)$ & $6.81(5.33,8.71)$ \\
\hline Pulmonary hypertension & $147(10 \%)$ & $70(2 \%)$ & $7.78(5.81,10.41)$ \\
\hline Pulmonary hypertension diagnosis & $134(9 \%)$ & $61(1 \%)$ & $9.04(5.90,10.96)$ \\
\hline Inhaled nitric oxide & $57(4 \%)$ & $33(1 \%)$ & $5.98(3.88,9.23)$ \\
\hline Sildenafil & $10(1 \%)$ & $0(0 \%)$ & N/A \\
\hline
\end{tabular}

